\title{
Tumour Volume Assessment in Gastric Cancer
}

\author{
Tatjana Bogdanova*, Arnis Abolins*, Andrejs Vanags**, Janis Gardovskis**, Ilze Strumfa* \\ *Department of Pathology, Riga Stradins University, Latvia \\ **Department of Surgery, Rīga Stradins University, Latvia
}

\begin{abstract}
SUMMARY
Introduction. Gastric cancer is a frequent malignant tumour worldwide along with lung, colorectal, and breast carcinoma. It is characterised by male predominance and peaks at the age of $70-75$ years. Gastric carcinoma is also an important cause of oncological mortality. Among the limited treatment options of this tumour, radical surgical intervention is the mainstay and can occasionally result in extended survival. Nevertheless, the 5-year survival of gastric cancer patients nowadays is still low, approaching only $22 \%$, therefore more exact prognostic assessment of the surgically treated patients must be elaborated. Tumour volume has been evaluated in other solid neoplasms. However, the application of this parameter in gastric cancer is still unclear.
\end{abstract}

Aim of the study is to measure gastric cancer volume in the surgical material and to assess the results regarding pTN classification in order to develop basic estimates of tumour volume applicability.

Material and methods. The research was designed as a retrospective study including 88 consecutive potentially radically surgically treated gastric cancer cases. The tumour volume was calculated using the three-dimensional ellipsoid formula. The cases were divided into 5 classes by the obtained volume and characterised by pTN classification and grade. Descriptive statistical analysis was performed. To detect statistically significant differences, the $95 \%$ confidence interval was calculated by CIA software and the findings were further confirmed by the $x 2$ test. Any difference was considered significant, if $p$ value was less than 0.05 .

Results. The largest number of cases presented with the smallest tumour volume not exceeding $5 \mathrm{~cm}^{3}$, namely, 24 cases or $27.3 \%$ $[95 \%$ confidence interval $=19.1-38.3]$. The pT1 and pT2 carcinomas significantly more frequently were smaller than $5 \mathrm{~cm}^{3}: 56.5 \%$ [36.8 - 74.4] in contrast with $15.4 \%$ [8.6 - 26.1] among pT3 - pT4. There was also notable association between the tumour volume and presence of regional metastases $(p<0.001)$ as all pNO tumours invariably were smaller than $10 \mathrm{~cm}^{3}$.

Conclusions. Smaller tumour volume was statistically significantly associated with a less extensive local spread by pT. The pNO finding was limited to smaller carcinomas not exceeding the volume of $10 \mathrm{~cm}^{3}$. The association between the tumour volume and pTN parameters indirectly indicates the prognostic value.

Key words: gastric cancer, tumour volume

\section{INTRODUCTION}

Gastric carcinoma is a frequent cancer worldwide along with lung, colorectal, breast and other carcinomas. It ranks $4^{\text {th }}$ by incidence comprising $7.8 \%$ of new malignant tumours (Price et al., 2012). The male:female ratio is estimated 2:1. Regarding the age distribution, gastric cancer is relatively rare in young adults under 30 years of age. Its incidence increases with the age, reaching the highest peak at 70 - 75 years [Herszenyi and Tulassay 2010; Centre for Disease Prevention and Control of Latvia, 2014]. Almost one million new cases were diagnosed in 2012, mostly in Asian countries. However, Eastern Europe is also characterised by particularly high incidence of gastric cancer. In Latvia, despite the continuous trend to lower occurrence (Figure 1), there were 589 new cases of gastric cancer in 2013 (Central Statistical Bureau of Latvia, 2014). Even more, gastric carcinoma contributes to the oncological mortality ranking $2^{\text {nd }}$ among the malignant tumours by death cases and causing $9.7 \%$ of cancer-related mortality (Price et al., 2012). It is the leading cause of cancer-related death in Japan and also incites high mortality in Europe and America [Herszenyi and Tulassay, 2010]. The treatment options are limited. Surgery is the most promising option. However, the 5-year survival in the whole group of gastric cancer patients is only
22\% [Herszenyi and Tulassay, 2010]. Nevertheless, improvement of survival in some European countries has been observed both in more distant time period from 1960 to 1989 and in more recent years from 1980 to 2005 [Hansson et al., 1999; Amiri et al., 2011]. The search for new useful prognostic and predictive factors is thus important. Tumour volume could be one of these prognostic factors.

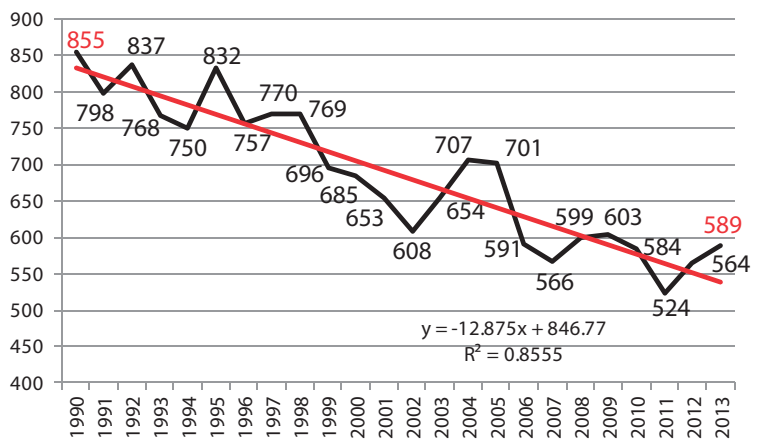

Fig. 1. The number of new gastric cancer cases in Latvia, 1990 - 2013 
In some cancers, including breast, lung and prostate carcinoma, the tumour volume has been measured using computed tomography, ultrasound and gross measurements. Regarding certain carcinomas, the tumour volume has shown a prognostic value although the findings are controversial [Wolters et al., 2010; Zhao et al., 2010]. There are only few studies about gastric carcinoma volume measuring using ultrasound or maximal tumour diameter as prognostic parameter [Giuliani et al., 2003; Futawatari et al., 2008]. Occasionally, tumour volume measurement in gastric cancer has been applied to document the tumour growth over 7 years in a patient refusing from treatment [Ubukata et al., 2004].

In Latvia, gastric cancer volume measurement in surgically resected tumours has not been performed and reported previously. In this study we analysed gastric cancer volume in relation to pTN classification.

\section{AIM OF THE STUDY}

The aim of our study is to detect the volume of potentially radically resected gastric carcinoma as well as assess the obtained data regarding pTN classification and tumour grade in order to develop basic estimates of tumour volume applicability.

\section{MATERIAL AND METHODS}

The research was designed as a retrospective study, including 88 consecutive potentially radically surgically treated gastric cancer patients from a single university hospital within the time period from 2010 to 2013 year. The cases were identified by archive search. The morphological examination has been performed by standardized protocol for gross and microscopic investigation. The gross size of tumours was measured in three dimensions (length, L; height, H; width, W). Cancers of gastrooesophageal junction and gastric cardia as well as secondary or non-epithelial gastric tumours were excluded from the study. However, no constraints were applied regarding cancer location in the stomach.

The tumour histogenesis and cancer differentiation by grade (G) was analysed in accordance with World Health Organisation classification and criteria [Bosman et al., 2010]. In short, adenocarcinoma was defined as a malignant epithelial tumour of the gastric mucosa displaying glandular differentiation. It was graded as follows: well differentiated (Gl), an adenocarcinoma with well-formed glands; moderately differentiated (G2): an adenocarcinoma showing intermediate morphological structure between well and poorly differentiated; poorly differentiated (G3): a tumour composed of highly irregular glands that are recognized with difficulty, or single cells that remain isolated or are arranged in small or large clusters with mucin secretions or acinar structures. Well and moderately differentiated tumours can be collectively described as low grade carcinoma in contrast to high grade cancers including the more aggressive cases. Signet-ring cell carcinoma is defined as an epithelial tumour, in which more than $50 \%$ of the neoplastic cells possess the signet-ring cell morphology with intracytoplasmic mucin vacuoles and atypical nucleus; these cells are either isolated or grow in small, irregular groups [Bosman et al., 2010]. The pT (local tumour invasion depth in the gastric wall and/ or other organs) and pN (regional lymph node status) parameters were determined according to the $7^{\text {th }}$ edition of pTNM classification (2010) as described by Edge et al., 2010 and Compton et al., 2012.

The three-dimensional fundamental shape of tumours is assumed to be ellipsoid [Buckle et al., 2012]. Thus, tumour volume was calculated using the ellipsoid formula $3 / 4 \pi(\mathrm{L} / 2 * \mathrm{H} / 2 * \mathrm{~W} / 2)$, using the following gross measurements: tumour length, L; height, $\mathrm{H}$; width, W. The tumours were further divided into the following classes by the volume. Class I comprised tumours having volume less than $5 \mathrm{~cm}^{3}$; class II: 5 $10 \mathrm{~cm}^{3}$; class III: $10-20 \mathrm{~cm}^{3}$; class IV: $20-50 \mathrm{~cm}^{3}$; class V: $50-100 \mathrm{~cm}^{3}$ and class VI: more than $100 \mathrm{~cm}^{3}$. Descriptive statistical analysis was performed. The descriptive data were expressed as the mean value or the frequency. To detect statistically significant differences, the $95 \%$ confidence interval (CI) was calculated by CIA software (Altman et al., 2000) and the findings were further confirmed by the $\chi^{2}$ test. Any difference was considered statistically significant, if the $\mathrm{p}$ value was less than 0.05 .

\section{RESULTS}

The identified study group comprised 31 (35.2\%) female and $57(64.8 \%)$ male patients. The mean age was 65.8 years [95\% CI $=63.1-68.5]$, ranging from 24 to 88 years. The prevalent cancer type was adenocarcinoma (Figure 2) in 71 (80.7\%) patient, followed by signet-ring cell carcinoma in $17(19.3 \%)$ patients. The studied gastric cancer group showed the following tumour volume distribution. Class I comprised $27.3 \%$ [19.1 - 38.3] of gastric carcinoma cases; class II: $15.9 \%$ [9.1 - 25.1]; class III: $18.2 \%$ [10.827.5]; class IV: $13.6 \%$ [7.4-22.5]; class V: $14.8 \%$ [8.223.9] and class VI: $10.2 \%$ [5.8 - 19.9].

The tumour volume relation to the local cancer spread (characterised by pT) is shown in Table 1. The smallest tumour volume (class I) was statistically significantly more frequent finding in the joint group of pTl and pT2 cases in contrast to pT3 and pT4 carcinoma. Tumour volume class III and IV dominated in the pT3 pT4 carcinoma group. pT3 - pT4 tumours composed $82.4 \%$ [59.0 - 93.8] and 100\% [79.6-100.0] of III and IV tumour volume class cancers, respectively.

Assessing the status of regional lymph nodes in the general study group, pN0 and pN3 were the most frequent findings. There were 22 patients without metastases in regional lymph nodes (pNO) and 32 patients affected by pN3 spread, constituting $25 \%$ [17.1 - 35.0] and 36.3\% [27.1 - 46.8] of the whole group, respectively. The mean number of retrieved lymph nodes was 12.0 [7.9 - 16.2] in pNO and 20.5 [17.4-23.5] in $\mathrm{pN}$ positive group. 
Table 1. Tumour volume relation to the local spread of gastric carcinoma

\begin{tabular}{|l|c|c|}
\hline $\begin{array}{l}\text { Tumour } \\
\text { volume } \\
\text { class }\end{array}$ & Frequency, \% [95\% confidence interval] \\
\cline { 2 - 3 } I & $56.6[36.8-74.4]$ & pT3, pT4 \\
\hline II & $17.4[7.0-37.1]$ & $12.3[6.4-22.5]$ \\
\hline III & $13.0[4.5-32.1]$ & $21.5[13.3-33.0]$ \\
\hline IV & 0 & $23.0[14.5-34.6]$ \\
\hline V & $4.3[0.8-21.0]$ & $17.0[9.7-27.8]$ \\
\hline VI & $8.7[2.4-26.8]$ & $10.8[5.3-20.1]$ \\
\hline
\end{tabular}

Abbreviations in the Table: pTl, gastric carcinoma invades gastric lamina propria mucosae, lamina muscularis mucosae, or submucosa; pT2, gastric carcinoma invades gastric muscular layer (lamina muscularis propria); pT3, gastric carcinoma invades subserosal connective tissue or penetrates muscular layer with extension into the gastrocolic or gastrohepatic ligaments, or into the greater or lesser omentum; pT4, gastric carcinoma invades serosa or any adjacent organ or structure: spleen, transverse colon, liver, diaphragm, pancreas, abdominal wall, adrenal gland, kidney, small intestine, and retroperitoneum.

All pN0 tumours, namely, 100.0\% [85.1 - 100.0], belonged to the I and II tumour volume class, with equivalent distribution: $50.0 \% \quad[30.7 \quad-$ 69.3] in each class. The larger tumour volume classes were not found among pN0: $0.0 \%$ [0.0 5.5]. The III - V tumour volume class frequently presented with a numerous (pN3) metastases in the regional lymph nodes: $63.6 \%$ [35.4 - 84.8], 72.7\% [43.4-90.3] and 66.7\% [39.1 - 66.2], respectively. All gastric cancer cases exceeding the volume of $10 \mathrm{~cm}^{3}$ (class III and larger) had developed regional lymph node metastases. Comparing the $\mathrm{pNO}$ and $\mathrm{pN}$ positive groups, the $\mathrm{p}$ value was $<0.001$. The relation of tumour volume to the regional lymph node status by $\mathrm{pN}$ is presented in Table 2 .

Table 2. The relation of gastric carcinoma volume to the regional lymph node status

\begin{tabular}{|c|c|c|c|c|}
\hline \multirow{2}{*}{$\begin{array}{l}\text { Tumour } \\
\text { volu- } \\
\text { me } \\
\text { class }\end{array}$} & \multicolumn{4}{|c|}{ Frequency, $\%$ [95\% confidence interval] } \\
\hline & pNO & $\mathrm{pNl}$ & $\mathrm{pN} 2$ & $\mathrm{pN} 3$ \\
\hline $\mathrm{I}$ & $\begin{array}{c}50.0 \\
{[30.7-69.3]}\end{array}$ & $\begin{array}{c}40.0 \\
{[19.8-64.3]} \\
\end{array}$ & $\begin{array}{c}21.1 \\
{[8.5-43.3]}\end{array}$ & $\begin{array}{c}31.2 \\
{[18.0-48.6]}\end{array}$ \\
\hline II & $\begin{array}{c}50.0 \\
{[30.7-69.3]}\end{array}$ & $\begin{array}{c}20.0 \\
{[7.0-45.2]} \\
\end{array}$ & $\begin{array}{c}10.5 \\
{[2.9-31.4]}\end{array}$ & $\begin{array}{c}25.0 \\
{[13.3-42.1} \\
\end{array}$ \\
\hline III & 0 & 0 & $\begin{array}{c}21.1 \\
{[8.5-43.3]} \\
\end{array}$ & $\begin{array}{c}43.7 \\
{[28.2-60.7]} \\
\end{array}$ \\
\hline IV & 0 & $\begin{array}{c}13.3 \\
{[3.7-37.9]}\end{array}$ & $\begin{array}{c}15.8 \\
{[5.5-37.6]}\end{array}$ & $\begin{array}{c}46.8 \\
{[30.9-63.6]}\end{array}$ \\
\hline V & 0 & $\begin{array}{c}13.3 \\
{[3.7-37.9]}\end{array}$ & $\begin{array}{c}21.1 \\
{[8.5-43.3]}\end{array}$ & $\begin{array}{c}34.3 \\
{[20.4-51.7]}\end{array}$ \\
\hline
\end{tabular}

\begin{tabular}{|l|c|c|c|c|}
\hline VI & 0 & 13.3 & 10.5 & 21.8 \\
& 0 & {$[3.7-37.9]$} & {$[2.9-31.4]$} & {$[11.0-38.6]$} \\
\hline
\end{tabular}

Abbreviations in the Table: pN0, no gastric carcinoma metastases in regional lymph nodes; $\mathrm{pN} 1$, metastases in $1-2$ regional lymph nodes; $\mathrm{pN} 2$, metastases in $3-$ 6 regional lymph nodes; pN3, metastases in 7 or more regional lymph nodes.

Analysing the cancer grade, low grade cancers (the joint group of G1 and G2) were characterised by predominantly small tumour volume (I - II tumour volume class) that was found in $47.6 \%$ [28.3 - 67.6]. However, the trend lacked statistical significance $(\mathrm{p}=$ 0.1 ). The tumour volume distribution in relation to the grade is presented in Table 3.

Table 3. Tumour volume relation to the grade of gastric carcinoma

\begin{tabular}{|c|c|c|}
\hline \multirow{2}{*}{$\begin{array}{c}\text { Tumour } \\
\text { volume } \\
\text { class }\end{array}$} & \multicolumn{2}{|c|}{ Frequency, \% [95\% confidence interval] } \\
\hline & $\begin{array}{l}\text { Low grade (G1 } \\
\text { and } \mathrm{G} 2 \text { ) carcinoma }\end{array}$ & $\begin{array}{l}\text { High grade (G3 and } \\
\text { G4) carcinoma }\end{array}$ \\
\hline I & $23.8[10.6-45.0]$ & $28.4[19.0-40.1]$ \\
\hline II & $23.8[10.6-45.0]$ & $13.4[7.2-23.6]$ \\
\hline III & $14.3[5.0-34.6]$ & $19.4[11.7-30.4]$ \\
\hline IV & $14.3[5.0-34.6]$ & $14.9[8.3-25.3]$ \\
\hline $\mathrm{V}$ & $19.0[7.7-40.0]$ & $11.9[6.2-21.8]$ \\
\hline VI & $4.8[1.0-22.7]$ & $11.9[6.2-21.8]$ \\
\hline
\end{tabular}

Abbreviations in the Table: G1, well differentiated gastric adenocarcinoma; G2, moderately differentiated gastric adenocarcinoma; G3, poorly differentiated gastric adenocarcinoma; G4, undifferentiated gastric carcinoma.

\section{DISCUSSION}

Gastric carcinoma is a frequent malignant tumour. The best choice of treatment is surgical approach gastrectomy or subtotal gastrectomy along with oncologically appropriate lymphadenectomy. Most of gastric cancer patients present with an advanced tumour due to the clinically silent cancer grow and the lack of persuasive clinical manifestations in early stages. This explains the low survival rate among gastric cancer patients [Yakirevich and Resnick, 2013]. The tumour volume remains a matter of debates in the oncological research. In certain solid tumours, independent prognostic value of this parameter is suggested by some and denied by other researchers [Hahn-Stromberg et al., 2009]. Moreover, dynamic volumetric tumour assessment has been successfully used to evaluate the presence of certain mutations [Zhao et al., 2010]. Thus, intrinsic association between the tumour volume and the cardinal tumour features determining also the prognosis should be suspected. In gastric cancer, the simple stratification of tumours into small and large size has been recently shown to have prognostic significance [ $\mathrm{Zu}$ et al., 2013]. The 

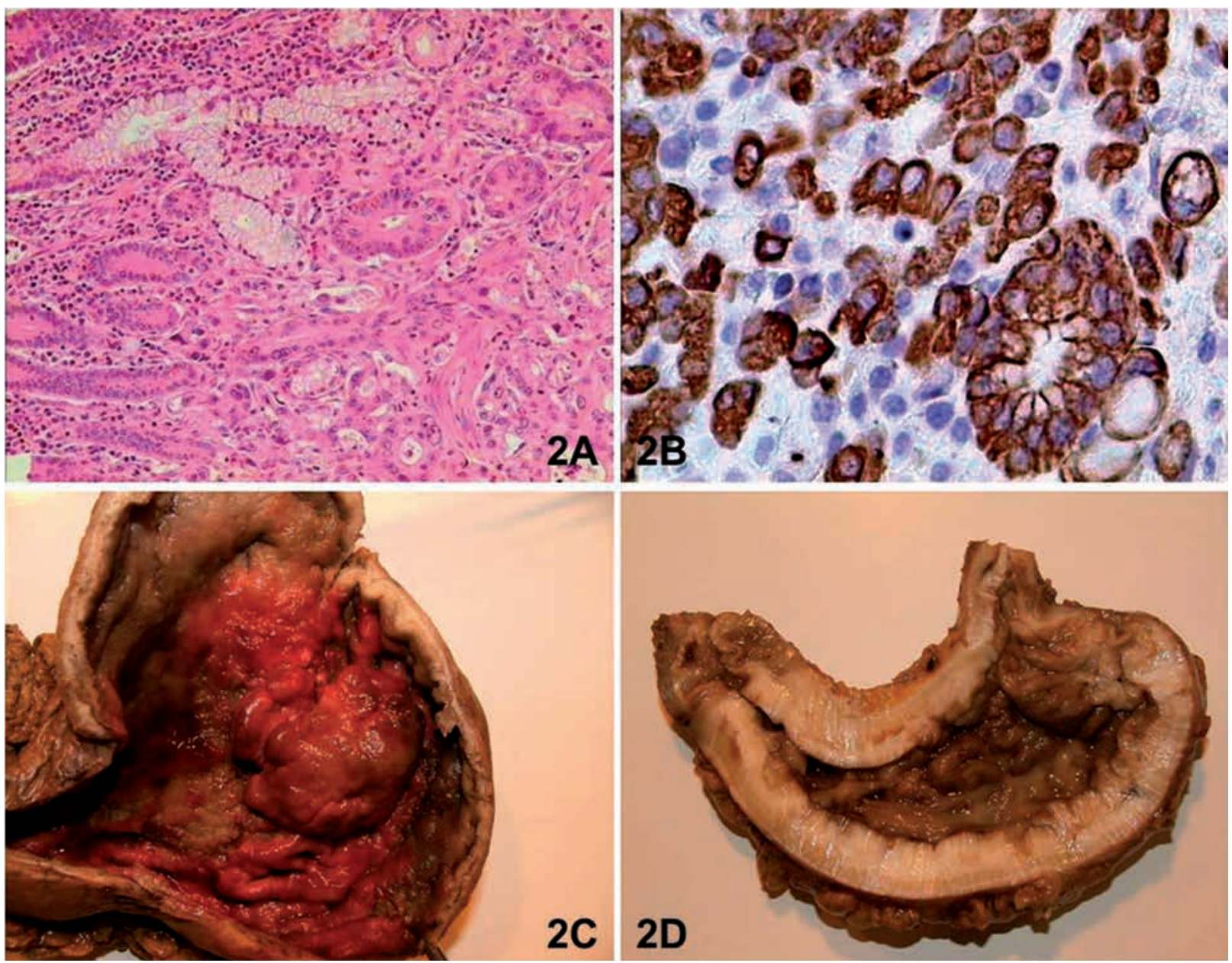

Fig. 2. The microscopic and gross view of gastric cancer. $2 \mathrm{~A}$, Adenocarcinoma invading the gastric mucosa. Note the glandular architecture along with cell anaplasia. Haematoxylin-eosin, original magnification 100x. 2B, Signet ring cell carcinoma in the gastric mucosa. Immunoperoxidase, anti-cytokeratin AE 1/ AE3, original magnification 400x; 2C, Intestinal type gastric cancer. Note the dominant mass. 2D, Diffuse gastric cancer widely infiltrating the gastric wall and resulting in large single size measurement. Note the remarkable spatial heterogeneity.

largest diameter of the tumour has been identified as an independent prognostic factor both by univariate and multivariate analysis [Giuliani et al., 2003]. Considering the remarkable spatial heterogeneity of gastric cancer, shown also in the Figure 2 and corresponding to the basic classifications of gastric cancer, we suggest that gastric carcinoma volume measurement could be more accurate parameter. As demonstrated by our results, volume measurements in surgical material can be reliably performed. Volume measurement by three-dimensional endoscopic ultrasonography has been studied as a risk factor of lymph node metastasis in early gastric cancer [Kikuchi et al., 2005; Futawatari et al., 2008]. Our findings are in accordance with this conclusion. Tumour size also has been assessed in advanced gastric cancer in the lower third of the stomach [Wang et al., 2012]. In accordance with these data, we have already shown statistically significant association between small tumour volume and early local cancer invasion pT1 - pT2.

\section{CONCLUSIONS}

1. The present study showed that gastric cancer volume can be routinely calculated using threedimensional ellipsoid formula. Using these results surgically treated gastric cancer cases can be grouped into volume classes. The grouping provides basis for optimal further analysis, class comparison and prognostic evaluation.

2. Smaller tumour volume was statistically significantly associated with less extensive local spread, reflected by lower pT parameter.

3. The gastric cancer cases having no metastases in regional lymph nodes were limited to tumour volume less than $10 \mathrm{~cm}^{3}$ and all tumours 
exceeding this volume had developed regional lymph node metastases. These data indirectly suggest that tumour volume is pathogenetically and prognostically important factor.

\section{Conflict of interest: None}

\section{REFERENCES}

1. Altman DG, Machin D, Bryant TN, Gardner RJ. Statistics with confidence. 2nd ed. Bristol: BMJ Books; 2000

2. Amiri M, Janssen F, Kunst AE. The decline in stomach cancer mortality: exploration of future trends in seven European countries // Eur J Epidemiol, $2011 ; 26: 23-28$

3. Bosman FT, Carneiro F, Hruban RH, Theise ND. World Health Organisation classification of tumours of the digestive system, 4th ed. Lyon: IARC Press; 2010

4. Buckle T, van den Berg NS, Kuil J, Bunschoten A, Oldenburg J, Borowsky AD, Wesseling J, Masada R, Oishi S, Fujii N, van Leeuwen FWB. Non - invasive longitudinal imaging of tumor progression using $a^{111}$ indium labelled CXCR4 peptide antagonist // Am J Nucl Med Mol Imaging, 2012; 2:99 - 109

5. Central Statistical Bureau of Latvia: http://www. csb.gov.lv/dati/statistikas-datubazes-28270.html (accessed 08.08.2014. 21:30)

6. Centre for Disease Prevention and Control (CDPC) of Latvia: http://www.spkc.gov.lv/veselibasaprupes-statistika (accessed 09.08.2014. 21:10)

7. Compton CC, Byrd DR, Garcia-Aguilar J, Kurtzman $\mathrm{SH}$, Olawaiye A, Washington MK. AJCC Cancer Staging Atlas, 2nd ed. NewYork: Springer; 2012

8. Edge SB, Byrd DR, Compton CC, Fritz AG, Greene FL, Trotti A III. AJCC cancer staging manual, 7th ed. New York: Springer; 2010

9. Futawatari N, Kikuchi S, Sakuramoto S, Kida M, Watanabe M. A new diagnostic method for early gastric cancer: volume measurement by 3-dimensional endoscopic ultrasonography in early gastric cancer and its clinical significance // Anticancer Res, 2008; 28:2907 - 2912

10. Giuliani A, Caporale A, Di Bari M, Demoro M, Gozzo P, Corona M, Miccini M, Ricciardulli T, Tocchi A. Maximum gastric cancer diameter as a prognostic indicator: univariate and multivariate analysis // J Exp Clin Cancer Res, 2003; 22:531 - 538

11. Hahn-Stromberg V, Edvardsson H, Bodin L, Franzen L. Tumor volume of colon carcinoma is related to the invasive pattern but not to the expression of cell adhesion proteins // APMIS, 2009;1 17:205-211

12. Hansson LE, Sparen P, Nyren O. Survival in stomach cancer is improving: results of a nationwide population-based Swedish study // Ann Surg, 1999; 230:162 - 169

13. Herszenyi L, Tulassay Z. Epidemiology of gastrointestinal and liver tumors // Eur Rev Med Pharmacol Sci, 2010; 14:249 - 258

14. Kikuchi S, Kida M, Kobayashi K, Yano T, Sakuramoto S, Watanabe M, Kubota K, Isobe Y. New diagnostic imaging of gastrointestinal tumours: a preliminary study of three-dimensional tumor structure and volumetry // Anticancer Res, 2005; 25:2935 - 2941

15. Price TJ, Shapiro JD, Segelov E, Karapetis CS, Pavlakis N, van Cutsem E, Shah MA, Kang YK, Tebbutt NC. Management of advanced gastric cancer // Expert Rev Gastroenterol Hepatol, 2012; 6:199- 208

16. Ubukata H, Katano M, Tabuchi T. A case of untreated gastric cancer followed for 7 years // Gastrointest Endosc, 2004; 60:476 - 480

17. Wang HM, Huang CM, Zheng CH, Li P, Xie JW, Wang JB, Lin JX, Lu J. Tumor size as a prognostic factor in patients with advanced gastric cancer in the lower third of the stomach // World J Gastroenterol, 2012; $18: 5470-5475$

18. Wolters $\mathrm{T}$, Roobol MJ, van Leeuwen PJ, van den Bergh RC, Hoedemaeker RF, van Leenders GJ, Schroder FH, van der Kwast TH. Should pathologists routinely report prostate tumour volume? The prognostic value of tumour volume in prostate cancer // Eur Urol, 2010; 57:821 - 829

19. Yakirevich E, Resnick MB. Pathology of gastric cancer and its precursor lesions // Gastroenterol Clin North Am, 2013; 42:261 - 284

20. Zhao B, Oxnard GR, Moskowitz CS, Kris MG, Pao W, Guo P, Rusch VM, Ladanyi M, Rizvi NA, Schwartz LH. A pilot study of volume measurement as a method of tumor response evaluation to aid biomarker development // Clin Cancer Res, 2010; $16: 4647-4653$

21. Zu H, Wang F, Ma Y, Xue Y. Stage-stratified analysis of prognostic significance of tumor size in patients with gastric cancer // PLoS One, 2013; 8:e54502

\section{Address:}

Tatjana Bogdanova,

Department of Pathology, Riga Stradins University,

Dzirciema Street 16, LV 1007, Riga, Latvia

E-mail: Tatjana.Bogdanova@rsu.lv 